\title{
The Correlation of Texture and the Formation of the Adiabatic Shear Band in 7XXX Aluminum Alloy during Dynamic Loading
}

\author{
Xiaodong Wu (iD) \\ State Key Laboratory of Advanced Design and Manufacturing for Vehicle Body, College of Mechanical and Vehicle Engineering, \\ Hunan University, Changsha 410082, China
}

Correspondence should be addressed to Xiaodong Wu; wuxiaodong@hnu.edu.cn

Received 31 May 2021; Accepted 6 July 2021; Published 17 July 2021

Academic Editor: Shiping Wen

Copyright (c) 2021 Xiaodong Wu. This is an open access article distributed under the Creative Commons Attribution License, which permits unrestricted use, distribution, and reproduction in any medium, provided the original work is properly cited.

The mechanical behavior of the extruded 7003-T6 aluminum profiles used as automotive buffer beams is investigated. The correlation of the texture and the formation of the adiabatic shear band is analyzed. Copper texture, $\mathrm{R}$ texture, and $\mathrm{S}$ texture are the main reasons for the anisotropy of mechanical behavior of the profile, resulting in that the stress of the profile along the extrusion direction is higher than that perpendicular to the extrusion direction. Through finite element modeling (FEM), it can be found that the adiabatic shear band is developed in the sample if the dynamic loading direction is parallel to the extrusion direction, but it does not appear if the loading direction is perpendicular to the extrusion direction. When the dynamic loading direction is parallel to the extrusion direction, higher stress results in a lower energy barrier for shear localization. Therefore, the formation of the adiabatic shear band is susceptible along but is not sensitive perpendicular to the extrusion direction. This study provides technical support for the service of 7003 aluminum alloy in automobiles, which has important academic and engineering application value.

\section{Introduction}

Aluminum alloy is an ideal lightweight material for automobiles because of its outstanding energy absorption performance and high specific strength. In recent years, more and more high-performance extruded 7XXX series aluminum alloy profiles are applied in the car body, such as 7003 aluminum alloy, as the automotive buffer beams. Therefore, the material's impact safety under high-speed impact is especially important for security reasons [1]. Thus, it is a major requirement to research the mechanical behavior of 7XXX series aluminum alloy under dynamic loading.

The general driving speed of a car is about $60 \mathrm{~km} / \mathrm{h}$, and the speed can reach $120 \mathrm{~km} / \mathrm{h}$ on the highway; the corresponding strain rate is about $1700 \mathrm{~s}^{-1} \sim 3400 \mathrm{~s}^{-1}$. Under highspeed impact, the thermo power is difficult to dissipate. The coupling of mechanical and thermal effects leads to special behavior of materials, such as adiabatic shear band, which is the precursor of fracture failure [2].

Automotive buffer beams are usually made by rolled or extruded aluminum alloy. The mechanical behavior of rolled or extruded materials is not the same in different directions, which means the mechanical behavior is anisotropic. Ye et al. [3] found that, in 6063-T4 aluminum alloy extruded bar, the stress of the $0^{\circ}$ sample is greater than the strength of $45^{\circ}$ and $90^{\circ}$ samples. Rahmaan et al. [4] studied 6013 and 7075 aluminum alloy sheets and reported that these alloys exhibited appreciable plastic anisotropy.

The researchers find that the anisotropy of materials is related to the texture's type and volume fraction formed during processing and heat treatment. This may also contribute to the directional formation of the adiabatic shear band. In recent years, researchers have noticed that the formation of adiabatic shear bands depends on the initial texture of the material [5-9]. Yang et al. [9] found that high density of texture introduced by rolling facilitates the formation of the adiabatic shear band in 7075 aluminum alloys. Therefore, it is essential to reveal the relationship between texture and adiabatic shear band formation.

Based on this intention, we studied the mechanical behavior of extruded 7003 aluminum alloys' profile. In this 
article, we present the results and analysis about the effects of texture on the adiabatic shear band formation.

\section{Materials and Methods}

We followed the methods of our previous work [10]. An extruded 7003 aluminum alloy profile was used as the raw material (Figure 1), and it was used as the automotive buffer beam. The composition of the profile is given in Table 1. The route of processing is as follows:

(1) T6 treatment by solutionizing at $470^{\circ} \mathrm{C}$ for $1 \mathrm{~h}$ and water quenching and, thereafter, artificial ageing at $120^{\circ} \mathrm{C}$ for $24 \mathrm{~h}$.

(2) Cutting cylindrical samples from the profile, the samples' size is $\Phi 3.5 \mathrm{~mm} \times 6 \mathrm{~mm}$. They were categorized into two types with the cylinder's axis perpendicular or parallel to the extrusion direction and designated as the $90^{\circ}$ sample and $0^{\circ}$ sample (Figure 1).

The quasi-static compressions were conducted by an Instron-3382 universal testing machine, and the strain rate is $0.001 \mathrm{~s}^{-1}$. The dynamic loading tests were conducted by using a split Hopkinson pressure bar (SHPB) device, the strain rate ranging from $1150 \mathrm{~s}^{-1}$ to $3300 \mathrm{~s}^{-1}$. Detailed parameters for the SHPB test can be taken from [11].

The texture of the material was detected by X-ray diffraction. The tests were conducted on the sample's midplane and were conducted by using a Siemens D500 diffractometer.

\section{Results}

The mechanical response of the 7003-T6 aluminum alloy profile during compression is evaluated by the stress-strain curves. Figure 2 shows the stress-strain curves of the samples under different loading status. It shows that, after the elastic deformation, the stress rises slowly with the strain, indicating a weak strain-hardening ability of the material. A similar mechanical response has also been found in other $7 X X X$ aluminum alloys $[12,13]$.

It can be seen from Figure 2 that the curves' slope of the $0^{\circ}$ sample and $90^{\circ}$ sample is equal to each other at the same strain rate. It means that the elastic modulus of the $0^{\circ}$ sample is equal to that of the $90^{\circ}$ sample. This is because the material's elastic modulus is mainly dependent on its chemical composition [14], so the elastic modulus is the same at different directions. The difference between the curves is that the yield point could be observed for the $0^{\circ}$ sample, while it is not obvious for the $90^{\circ}$ sample. For the phenomenon of yield points, the dislocation theory [15] suggests that a mass of dislocations is pinned by the grain boundary, diffusion phase, and impurities under plastic deformation. Therefore, greater external force is needed to overcome the pinning effect which leads to the upper yield point. When the force overcomes the pinning obstacles, the dislocations can move freely, resulting in the stress which drops to the lower yield point. The yield strength depends on the material itself; besides, the strain rate is also one of the important factors.
Consequently, it can be seen from Figure 2 that when the strain rate exceeds $2000 \mathrm{~s}^{-1}$, the yield point appears on the stress-strain curve of the $0^{\circ}$ sample. In addition, the loading mode is also an important factor. Different loading directions cause different relations between the force and displacement, leading to the possibility that the yield points appear or not. Therefore, no obvious yield points are observed in the curves of the $90^{\circ}$ sample.

Figure 2 also shows the results that the stress for the $0^{\circ}$ sample is always greater than that for the $90^{\circ}$ sample at the same strain rate, whether under dynamic loading or quasistatic deformation. It can be concluded that the alloy's mechanical behavior is obviously anisotropic.

The texture is analyzed by using the X-ray diffraction technique in order to reveal the causes of the anisotropic characteristics. The collected orientation distribution function (ODF) results are shown in Figure 3. As shown, the main texture is cube texture $\{011\}<100>$ with an intensity of 12 , copper texture $\{112\}<111>$ with an intensity of $9, \mathrm{~S}$ texture $\{123\}<634>$ with an intensity of 5.9 , and $R$ texture $\{124\}<211>$ with an intensity of 5.2 , which are the highprobability textures observed in aluminum alloys [16].

The yield strength can be expressed as [17]

$$
\sigma_{0.2}=\frac{\tau_{c}}{(\cos \varphi \cos \lambda)_{\max }} .
$$

$\sigma_{0.2}$ is the yield strength, $\tau_{c}$ is the critical shear stress, $\varphi$ is the angle of the slip plane and loading axis, $\lambda$ is the angle between the slip direction and the loading axis, and $\cos \varphi \cos \lambda$ is defined as the Schmid factor. Apparently, the yield strength is inversely proportional to the Schmid factor. The Schmid factor determines whether the slip system opens or not, thereby affecting the mechanical behavior in this direction. Therefore, it is necessary to calculate the Schmidt factor in different directions.

The major slip system of the aluminum alloy is $\{111\}$ $<110>$. The Schmid factor values are calculated, as shown in Tables 2 and 3. For cube texture $\{011\}<100>$, the maximum Schmid factors are 0.41 for both $0^{\circ}$ and $90^{\circ}$ samples. For copper texture $\{112\}<111\rangle$, the maximum Schmid factors are 0.42 and 0.47 for the $0^{\circ}$ and $90^{\circ}$ sample, respectively. For $S$ texture $\{123\}<634>$, the maximum Schmid factors are 0.27 and 0.41 for the $0^{\circ}$ and $90^{\circ}$ sample, respectively. For $\mathrm{R}$ texture $\{124\}<211>$, the maximum Schmid factors are 0.41 and 0.49 for the $0^{\circ}$ and $90^{\circ}$ sample, respectively. It can be concluded that the maximum Schmid factors are always lower for the $0^{\circ}$ sample than those for the $90^{\circ}$ sample. In this way, it explains why the $0^{\circ}$ sample always exhibits the higher strength.

It is very hard to monitor the real time of the SHPB test because the dynamic loading process is extremely fast. Therefore, the numerical simulation method is often employed to simulate the dynamic loading process and has been proved to be successful $[18,19]$. The finite element modeling (FEM) method is adopted in this paper. Before modeling, the constitutive model of the material is obtained, which is essential for FEM. The Johnson-Cook model is adopted which has been widely used for dynamic deformation cases $[20,21]$. The Johnson-Cook model is one of the 


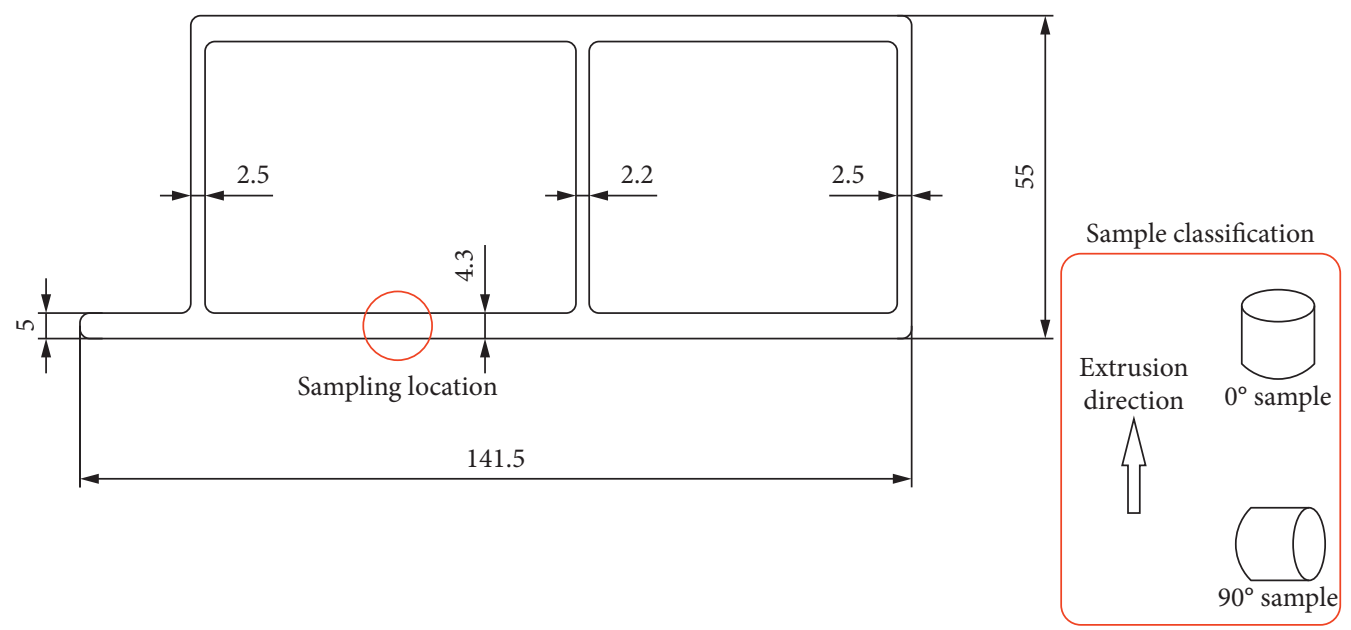

FIgURE 1: The drawing of the 7003 aluminum alloy profile and the location of sampling.

TABle 1: Chemical composition of the 7003 aluminum alloy profile (wt, \%).

\begin{tabular}{cccccccccc}
\hline $\mathrm{Zn}$ & $\mathrm{Mg}$ & $\mathrm{Cu}$ & $\mathrm{Si}$ & $\mathrm{Mn}$ & $\mathrm{Fe}$ & $\mathrm{Cr}$ & $\mathrm{Ti}$ & $\mathrm{Zr}$ & $\mathrm{Al}$ \\
\hline 5.6 & 1.00 & 0.13 & 0.05 & 0.13 & 0.15 & 0.001 & 0.025 & 0.13 & Residual \\
\hline
\end{tabular}

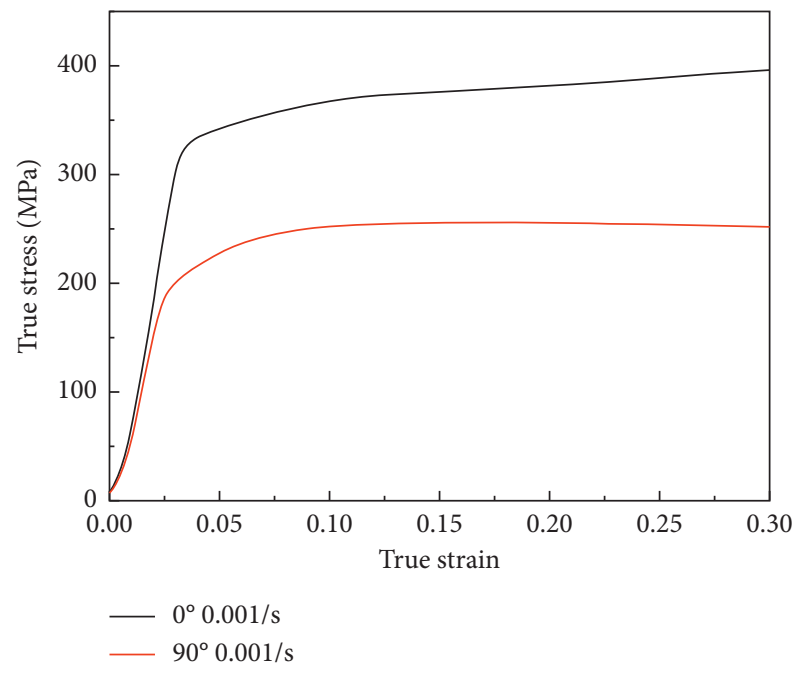

(a)

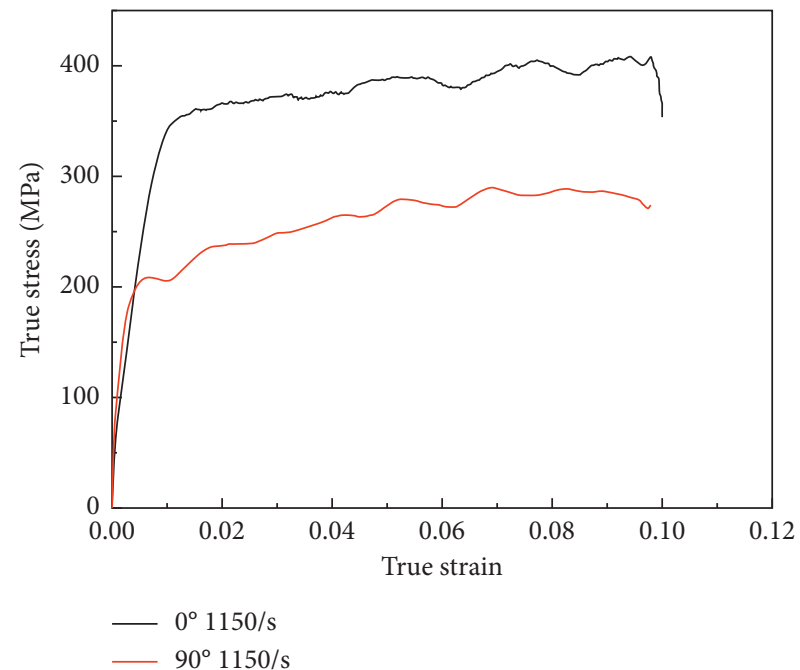

(b)

Figure 2: Continued. 


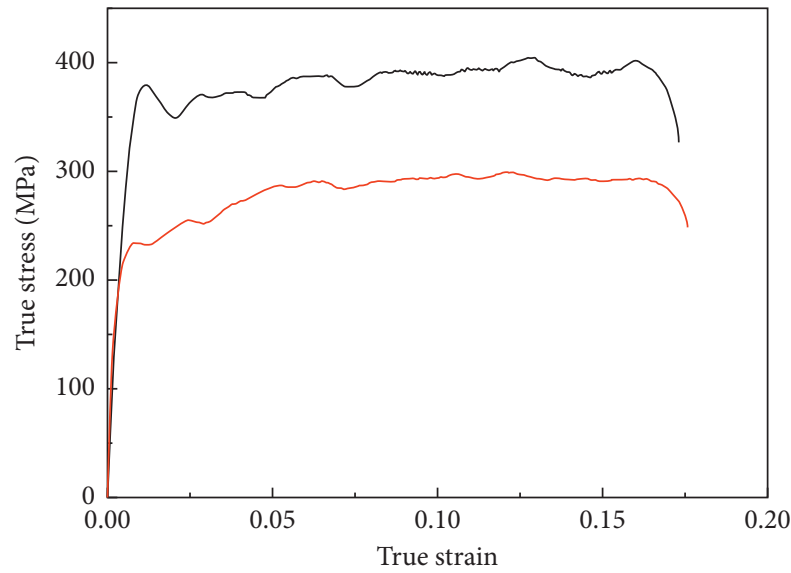

- $0^{\circ} 2000 / \mathrm{s}$

$-90^{\circ} 2000 / \mathrm{s}$

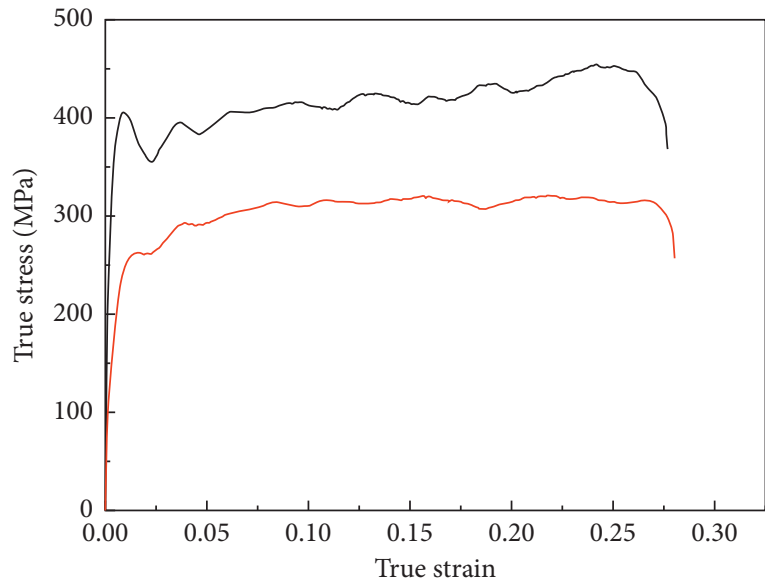

- $0^{\circ} 3300 / \mathrm{s}$

$-90^{\circ} 3300 / \mathrm{s}$

(c)

(d)

Figure 2: Comparison of true stress-strain curves between the $0^{\circ}$ sample and $90^{\circ}$ sample under different strain rates: (a) $0.001 \mathrm{~s}^{-1}$; (b) $1150 \mathrm{~s}^{-1}$; (c) $2000 \mathrm{~s}^{-1}$; (d) $3300 \mathrm{~s}^{-1}$.
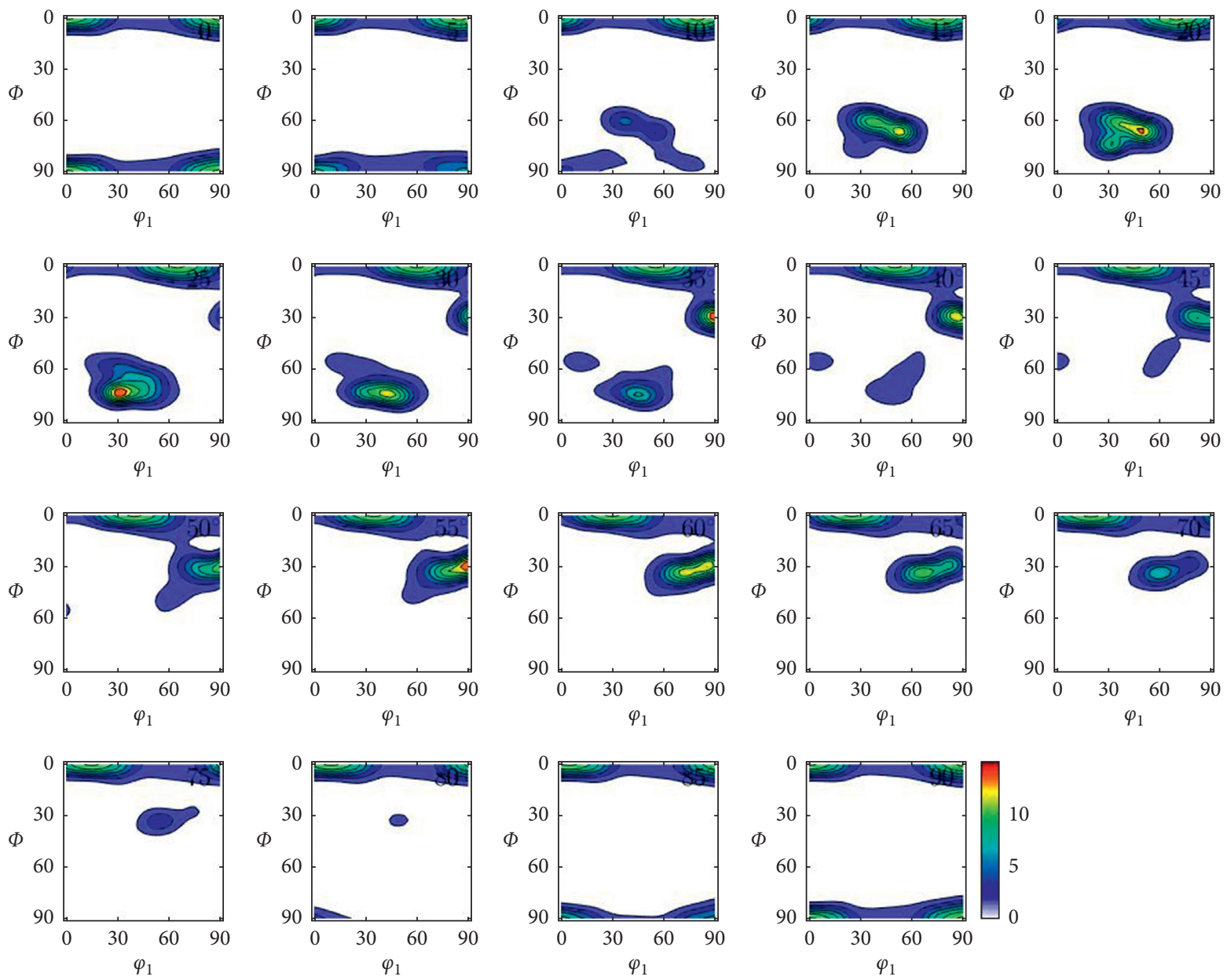

FIgURE 3: ODF of the extruded 7003-T6 aluminum alloy profile. 
TABLE 2: Schmid factor of the $\{111\}<110>$ slip system at different directions with $\{001\}<100>$ and $\{112\}<111>$ textures.

\begin{tabular}{cccccc}
\hline \multirow{2}{*}{ Slip system } & \multicolumn{5}{c}{ Schmid factor } \\
Slip plane & Slip direction & $0^{\circ}$ & $90^{\circ}$ & $0^{\circ}$ & $90^{\circ}$ \\
\hline \multirow{3}{*}{$(1-11)$} & 110 & 0.41 & 0 & 0.27 & 0.27 \\
& $10-1$ & 0.41 & -0.41 & 0 & -0.14 \\
& 011 & 0 & 0.41 & 0.27 & 0.41 \\
$(-111)$ & 110 & -0.41 & 0 & 0.27 & 0.27 \\
& 101 & -0.41 & 0.41 & 0.27 & 0.41 \\
$(111)$ & $01-1$ & 0 & -0.41 & 0 & -0.14 \\
& $1-10$ & 0.41 & 0 & 0 & 0 \\
& $10-1$ & 0.41 & -0.41 & 0 & -0.27 \\
$(11-1)$ & $01-1$ & 0 & -0.41 & 0 & -0.27 \\
& $1-10$ & 0.41 & 0 & 0 & 0 \\
& 101 & 0.41 & -0.41 & 0.27 & 0 \\
& 011 & 0 & -0.41 & 0.27 & 0 \\
\hline
\end{tabular}

TABLE 3: Schmid factor of the $\{111\}<110>$ slip system at different directions with $\{123\}<634>$ and $\{124\}<211>$ textures.

\begin{tabular}{cccccc}
\hline \multirow{2}{*}{ Slip system } & \multicolumn{4}{c}{ Schmid factor } \\
Slip plane & Slip direction & $0^{\circ}$ & $90^{\circ}$ & $0^{\circ}$ & $90^{\circ}$ \\
\hline \multirow{3}{*}{$(1-11)$} & 110 & 0.42 & 0.17 & 0.41 & 0.17 \\
& $10-1$ & 0.09 & -0.12 & 0.14 & -0.17 \\
& 011 & 0.33 & 0.29 & 0.27 & 0.35 \\
$(-111)$ & 110 & 0.06 & 0.35 & 0 & 0.29 \\
& 101 & 0.07 & 0.47 & 0 & 0.49 \\
$(111)$ & $01-1$ & -0.01 & -0.12 & 0 & -0.19 \\
& $1-10$ & 0.26 & -0.17 & 0.27 & -0.14 \\
& $10-1$ & 0.17 & -0.35 & 0.27 & -0.41 \\
$(11-1)$ & $01-1$ & -0.09 & -0.17 & 0 & -0.27 \\
& $1-10$ & 0.1 & 0 & 0.14 & 0.02 \\
& 101 & 0.33 & 0 & 0.41 & -0.10 \\
& 011 & 0.23 & 0 & 0.27 & -0.12 \\
\hline
\end{tabular}

most widely used constitutive models because it adopts a simple and effective expression and can be applied to various crystal structures, as shown in the following equation [20]:

$$
\sigma=\left[A+B \varepsilon^{n}\right]\left[1+C \ln \left(\frac{\dot{\varepsilon}}{\dot{\varepsilon}_{0}}\right)\right]\left[1-\left(\frac{T-T_{\text {room }}}{T_{\text {melt }}-T_{\text {room }}}\right)^{m}\right],
$$

where $\varepsilon$ is the plastic strain, $\dot{\varepsilon}$ is the strain rate, $\dot{\varepsilon}_{0}$ is the reference plastic strain rate, $T, T_{\text {room }}$, and $T_{\text {melt }}$ are the absolute temperature, room temperature, and melting point, and $A, B, n, C$, and $m$ are the parameters to be determined, respectively. Using the data obtained from Figure 2, the models are built by fitting the true stress-strain curves. The derived John-Cook model parameters are listed in Table 4.

FEM is then carried out by using the obtained constitutive material model to simulate the SHPB test. LS-DYNA 10.0 software is adopted in the numerical simulations of the SHPB test. The diameter and length of the bars are set the same as the experimental SHPB device. A velocity of $21 \mathrm{~m} / \mathrm{s}$, calculated from the strain rate of $3300 \mathrm{~s}^{-1}$ and sample sizes
TABLE 4: John-Cook model parameters of 7003 aluminum alloy.

\begin{tabular}{lccccc}
\hline & $A(\mathrm{MPa})$ & $B(\mathrm{MPa})$ & $C$ & $n$ & $m$ \\
\hline $0^{\circ}$ & 323 & 339 & 0.004 & 0.9 & 1.86 \\
$90^{\circ}$ & 183 & 224 & 0.01 & 0.55 & 1.4 \\
\hline
\end{tabular}

adopted in the SHPB test, is applied to the striking bar. The simulation results are shown in Figures 4 and 5. Figure 4 shows that high strain concentration is formed in the bottom right and top left corner of the sample, and then the deformation concentration area gradually expands to the center of the $0^{\circ}$ sample. It also shows that the maximum strain in the high strain concentration area is much bigger than the strain in other areas. Figure 5 shows that lower strain concentration is formed in the center of the $90^{\circ}$ sample. It also shows that there is little difference between the maximum strain in the high strain concentration area and the strain in other areas. Therefore, an adiabatic shear band develops in the $0^{\circ}$ sample, but it does not appear in the $90^{\circ}$ sample.

Grady [22] believed that, to form an adiabatic shear band, a critical energy barrier is always needed to overcome. The smaller the energy barrier is, the easier adiabatic shearing occurs in the material. He proposed a method for estimating and comparing the energy dissipated per unit area of an adiabatic shear band. It is expressed as the following:

$$
G=\frac{\rho c}{\alpha}\left(\frac{9 \rho^{3} c^{2} \chi^{3}}{\tau_{y}^{3} \alpha^{2} \dot{\gamma}}\right)^{1 / 4}
$$

where $\rho$ is the density, $c$ is the specific heat, $\chi$ is the thermal softening coefficient, $\alpha$ is the thermal diffusion coefficient, and $\tau_{y}$ is the flow stress. For $0^{\circ}$ and $90^{\circ}$ samples, the flow stress $\tau_{y}$ is different, while the other parameters are the same in the above equation. As shown in Figure 2, at the same strain, the $\tau_{y}$ value for the $0^{\circ}$ sample is greater than that for the $90^{\circ}$ sample. Consequently, the adiabatic shear band is more likely to occur in the $0^{\circ}$ sample. This is consistent with the shearing phenomenon observed in Figure 4. As stated above, the tendency of the 7003-T6 aluminum alloy to form the adiabatic shear band has been explained by the texture feature which results in high flow stress in the $0^{\circ}$ sample.

Figure 6 shows the ODF of the $0^{\circ}$ sample after dynamic loading. It can be seen that the main texture of the $0^{\circ}$ sample after dynamic loading is rotation cube texture $\{001\}<110>$ with an intensity of 5 , brass- $R$ texture $\{111\}<110>$ with an intensity of 2.9 , Goss texture $\{011\}<100>$ with an intensity of 2.5 , and cube texture $\{001\}<100\rangle$ with an intensity of 2.4 . Compared with Figure 3, the intensity of the cube texture decreases significantly after dynamic loading, while the intensity of the Goss texture and rotating cube texture increases. The reason for this change is that cube texture is an unstable orientation, under dynamic loading, and it will convert into Goss texture which is a stable orientation on the $\alpha$-orientation line. Since the adiabatic shear band is formed in the $0^{\circ}$ sample under dynamic loading, Goss texture is easy to nucleate in the adiabatic shear band, which makes the 


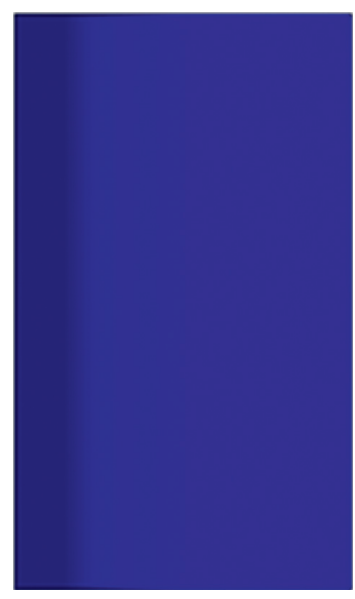

Effective plastic strain

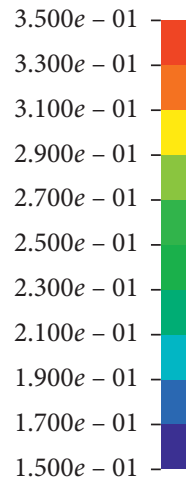

(a)

Effective plastic strain

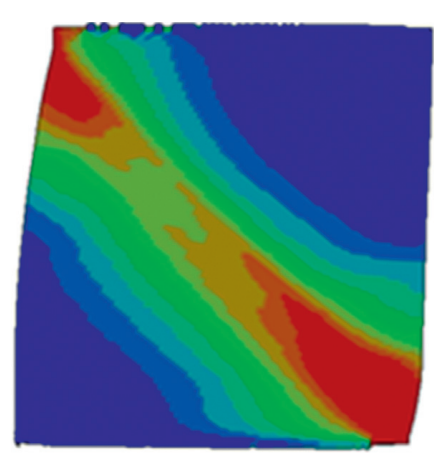

(c)

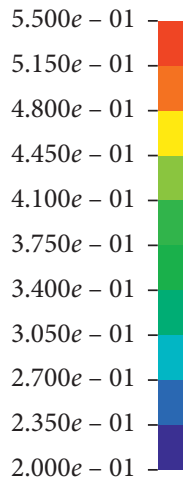

$2.000 e-01$

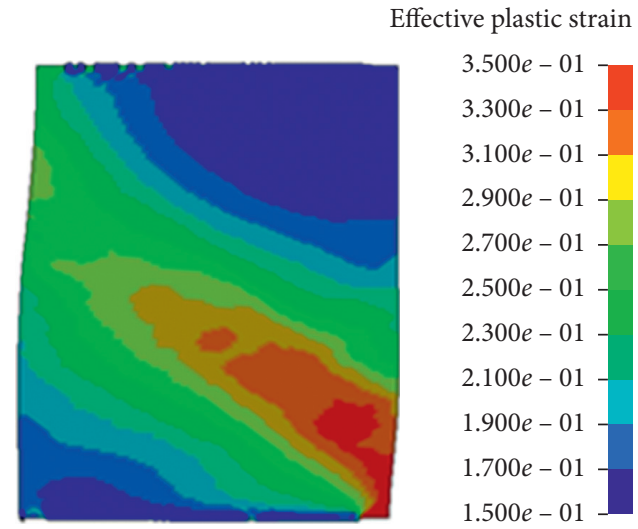

(b)

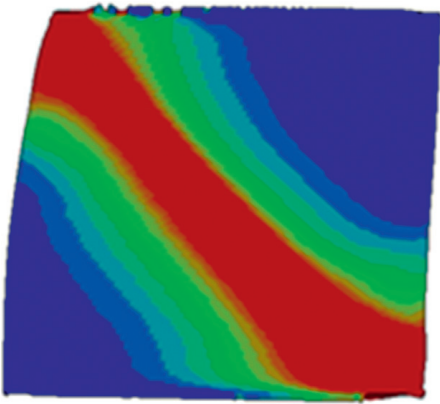

Effective plastic strain

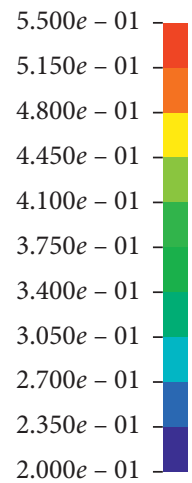

(d)

Figure 4: The strain distribution at different times ( $0^{\circ}$ sample, the strain rate is $3300 \mathrm{~s}^{-1}$ ): (a) $0.0525 \mathrm{~ms}$; (b) $0.12 \mathrm{~ms}$; (c) $0.1375 \mathrm{~ms}$; (d) $0.15 \mathrm{~ms}$.

Effective plastic strain

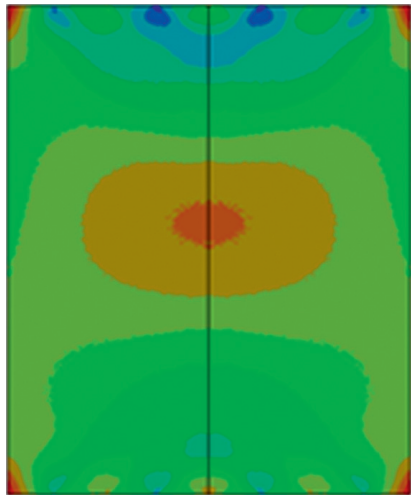

(a)

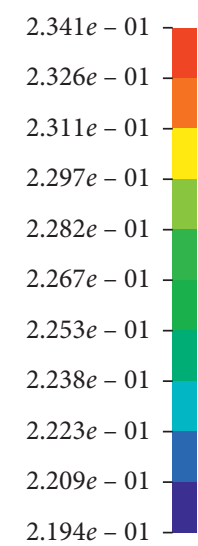

$2.194 e-01$

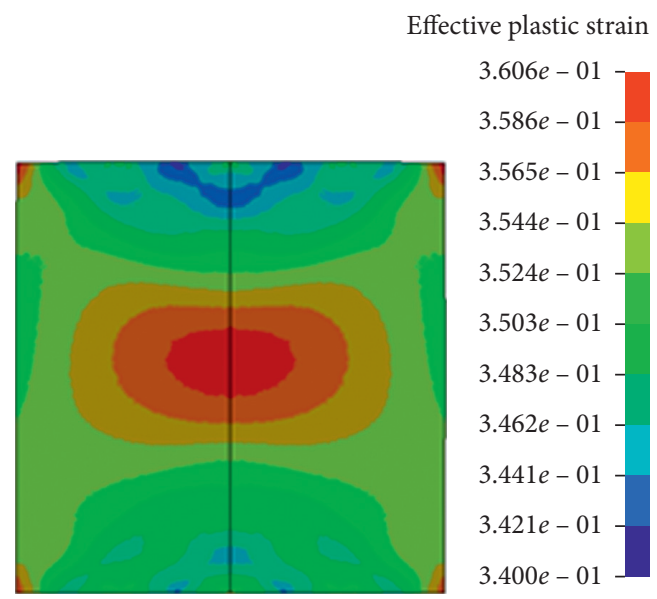

(b)

Figure 5: The strain distribution at different times ( $90^{\circ}$ sample, the strain rate is $3300 \mathrm{~s}^{-1}$ ): (a) $0.12 \mathrm{~ms}$; (b) $0.15 \mathrm{~ms}$.

intensity of the Goss texture increase significantly. In the process of dynamic loading, the grain rotation makes the slip plane turn perpendicular to the pressure axis. When the grain rotates to a specific direction, the stress will release due to dislocation slip. At this time, the driving force of grain rotation disappears, and the grain stops rotation, thus forming a shear texture $[23,24]$. With the increase of engineering strain, a large shear deformation occurs in the 

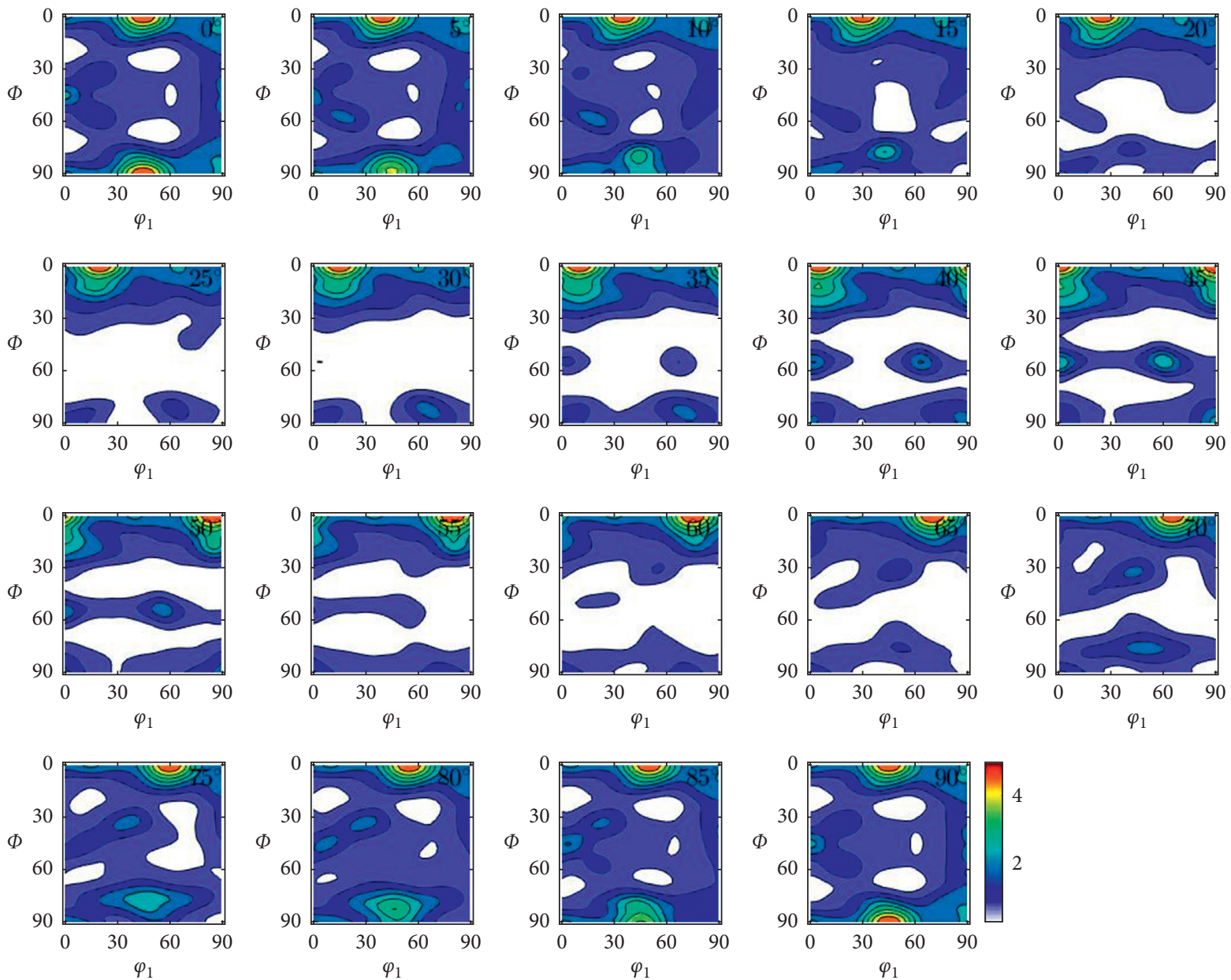

Figure 6: ODF of the $0^{\circ}$ sample after dynamic loading (the strain rate is $3300 \mathrm{~s}^{-1}$ and the engineering strain is 0.65 ).

sample, resulting in the formation of rotation cubic shear texture.

This texture evolution has also been found in the deformation process of other alloys [25-27]. Maurice et al. [25] studied the texture evolution of 3000 series aluminum alloy during hot rolling and found that when the strain rate is small, with the increase of deformation, the intensity of the $S$ texture and copper texture decreases, while the intensity of the brass and Goss texture increases; when the deformation rate is high, with the increase of deformation, the copper texture is almost unchanged, the intensity of the $S$ texture and Goss texture increases slightly, and the intensity of the brass texture increases significantly. This finding also shows that the dynamic loading is similar to the hot rolling process, which is a comprehensive process of heat power. When a certain strain is reached, adiabatic shear band may appear, which is a vantage position for recrystallization nucleation $[28,29]$, leading to the formation of recrystallization texture or the increase of its intensity.

\section{Conclusion}

Based on the above experimental and simulated results, the formation of the adiabatic shear band in the 7003-T6 aluminum alloy profiles can be discussed. The texture results the flow stress of the $0^{\circ}$ sample is greater than that of $90^{\circ}$ sample, thereby resulting in lower barrier energy and higher sensibility for the formation of the adiabatic shear band. The alloy's texture changes under dynamic loading, and the adiabatic shear band formation leads to the formation of recrystallization texture and shear texture.

\section{Data Availability}

No data were used to support this study.

\section{Conflicts of Interest}

The author declares that there are no conflicts of interest regarding the publication of this paper.

\section{Acknowledgments}

This work was supported by the National Natural Science Foundation of China (Grant nos. U1664252 and 51605234), the National Key Research and Development Program of China (Grant no. 2016YFB0101700), and the Open Research Fund of the State Key of Comprehensive Technology on 
Automobile Vibration and Noise \& Safety Control (Grant no. 1803J).

\section{References}

[1] S. Hou, Y. Zheng, J. Xie et al., "Optimization design of nj shaped guardrail based on collision safety consideration," International Journal of Computational Methods, vol. 11, no. 6, pp. 1-20, 2014.

[2] T. Wang, Z. L. Liu, Y. N. Cui et al., "A thermo-elastic-plastic phase-field model for simulating the evolution and transition of adiabatic shear band. Part I. Theory and model calibration," Engineering Fracture Mechanics, vol. 232, Article ID 107028, 2020.

[3] T. Ye, L. Li, X. Liu, W. Liu, P. Guo, and X. Tang, "Anisotropic deformation behavior of as-extruded 6063-T4 alloy under dynamic impact loading," Materials Science and Engineering: A, vol. 666, pp. 149-155, 2016.

[4] T. Rahmaan, J. Noder, A. Abedini et al., "Anisotropic plasticity characterization of 6000 and 7000 series aluminum sheet alloys at various strain rates," International Journal of Impact Engineering, vol. 135, pp. 103390.1-103390.20, 2020.

[5] T. Nguyen-Minh, J. J. Sidor, R. H. Petrov et al., "Shear banding and its contribution to texture evolution in rotated goss orientations of BCC structured materials," Iop Conference, vol. 81, p. 1, 2015.

[6] J. Peng, Z. Zhang, P. Guo et al., "The effect of contraction twins and shear bands on the texture evolution during isothermal annealing and its effect on mechanical properties of AZ31 magnesium alloys," Materials Science and Engineering: A, vol. 763, Article ID 138100, 2019.

[7] J. Li, R. Yu, J. Chen, F. Li, S. Liang, and M. Zhang, "Influence of load modes on the characteristics of severe plastic deformation based on crystal plasticity finite element method," Journal of Materials Engineering and Performance, vol. 30, no. 3, pp. 1981-1993, 2021.

[8] C. Seguí, E. Tauler, X. Planas, J. Moya, and M. Veveakis, "The interplay between phyllosilicates fabric and mechanical response of deep-seated landslides. The case of El Forn de Canillo landslide (Andorra)," Landslides, vol. 18, no. 1, pp. 145-160, 2020.

[9] Y. Yang, H. G. Zheng, Z. J. Shi, and Q. M. Zhang, "Effect of orientation on self-organization of shear bands in 7075 aluminum alloy," Materials Science and Engineering: A, vol. 528, no. 6, pp. 2446-2453, 2011.

[10] X. Wu, H. He, L. Zhang, L. Li, C. Xu, and W. Liu, "The influence of microstructural anisotropy on the formation of adiabatic shearing bands in extruded 7003 aluminum alloy profiles during high strain rate impaction," Advanced Engineering Materials, vol. 21, no. 8, Article ID 1900344, 2019.

[11] X. Wu, L. Li, W. Liu, S. Li, L. Zhang, and H. He, "Development of adiabatic shearing bands in 7003-T4 aluminum alloy under high strain rate impacting," Materials Science and Engineering: A, vol. 732, pp. 91-98, 2018.

[12] P. Zhou, Y. Song, L. Hua, J. Lu, J. Zhang, and F. Wang, "Mechanical behavior and deformation mechanism of 7075 aluminum alloy under solution induced dynamic strain aging," Materials Science and Engineering: A, vol. 759, pp. 498-505, 2019.

[13] T. Zhang, Z.-R. Guo, F.-P. Yuan, and H.-S. Zhang, "Investigation on the plastic work-heat conversion coefficient of 7075-T651 aluminum alloy during an impact process based on infrared temperature measurement technology," Acta Mechanica Sinica, vol. 34, no. 2, pp. 327-333, 2018.
[14] R. Snyders, E. Bousser, D. Music et al., "Influence of the chemical composition on the phase constitution and the elastic properties of RF-sputtered hydroxyapatite coatings," Plasma Processes \& Polymers, vol. 5, no. 2, pp. 168-174, 2010.

[15] V. Taupin, S. Varadhan, C. Fressengeas, and A. J. Beaudoin, "Directionality of yield point in strain-aged steels: the role of polar dislocations," Acta Materialia, vol. 56, no. 13, pp. 3002-3010, 2008.

[16] S. J. Hales and R. A. Hafley, "Texture and anisotropy in Al-Li alloy 2195 plate and near-net-shape extrusions," Materials Science and Engineering: A, vol. 257, no. 1, pp. 153-164, 1998.

[17] Y. N. Wang and J. C. Huang, "Anisotropic tensile properties at room and elevated temperatures in warm-extruded AZ61 magnesium alloy," Materials Science Forum, vol. 495-497, pp. 657-662, 2005.

[18] N. Jia, P. Eisenlohr, F. Roters, D. Raabe, and X. Zhao, "Orientation dependence of shear banding in face-centeredcubic single crystals," Acta Materialia, vol. 60, no. 8, pp. 3415-3434, 2012.

[19] S. A. Tajalli, M. R. Movahhedy, and J. Akbari, "Simulation of orthogonal micro-cutting of FCC materials based on ratedependent crystal plasticity finite element model," Computational Materials Science, vol. 86, pp. 79-87, 2014.

[20] J. Che, T. Zhou, Z. Liang et al., “An integrated Johnson-Cook and Zerilli-Armstrong model for material flow behavior of Ti$6 \mathrm{Al}-4 \mathrm{~V}$ at high strain rate and elevated temperature," Journal of the Brazilian Society of Mechanical Sciences and Engineering, vol. 40, no. 5, pp. 252-262, 2018.

[21] R. Chakrabarty and J. Song, "A modified Johnson-Cook material model with strain gradient plasticity consideration for numerical simulation of cold spray process," Surface and Coatings Technology, vol. 397, Article ID 125981, 2020.

[22] K. Minnaar and M. Zhou, "An analysis of the dynamic shear failure resistance of structural metals," Journal of the Mechanics and Physics of Solids, vol. 46, no. 10, pp. 2155-2170, 1998.

[23] R. Taufner, L. Lagoeiro, C. Cavalcante et al., "Deformation mechanisms accommodating progressive simple shear thrusting of quartzite and metacarbonate in the Southwestern Espinhao range, Brazil," Journal of South American Earth Sciences, vol. 107, Article ID 102944, 2020.

[24] S. Pal and M. Meraj, "Investigation of reorganization of a nanocrystalline grain boundary network during biaxial creep deformation of nanocrystalline $\mathrm{Ni}$ using molecular dynamics simulation," Journal of Molecular Modeling, vol. 25, no. 9, p. 282, 2019.

[25] C. Maurice, D. Piot, H. Klocker, and J. H. Driver, "Hot plane strain compression testing of aluminum alloys by channel-die compression," Metallurgical and Materials Transactions A, vol. 36, no. 4, pp. 1039-1047, 2005.

[26] J. Chen, J. Li, B. Tang et al., "Microstructure and texture evolution of a near $\beta$ titanium alloy Ti-7333 during continuous cooling hot deformation," Progress in Natural Science: Materials International, vol. 29, no. 1, pp. 50-56, 2019.

[27] J. Xun, G. Lin, H. Liu et al., "Texture evolution and dynamic recrystallization of $\mathrm{Zr}-1 \mathrm{Sn}-0.3 \mathrm{Nb}-0.3 \mathrm{Fe}-0.1 \mathrm{Cr}$ alloy during hot rolling," Acta Metallurgica Sinica (English Letters), vol. 33, no. 2, pp. 215-224, 2020.

[28] R. Wang, H. Zhang, L. Tang et al., "Adiabatic shear deformation behaviors of cold-rolled copper under different impact loading directions," Materials Science and Engineering: A, vol. 754, pp. 330-338, 2019.

[29] L. Choisez, L. Ding, M. Marteleur, H. Idrissi, T. Pardoen, and P. J. Jacques, "High temperature rise dominated cracking mechanisms in ultra-ductile and tough titanium alloy," $\mathrm{Na}$ ture Communications, vol. 11, no. 1, p. 2110, 2020. 